\title{
The kinetics of antibody binding to Plasmodium falciparum VAR2CSA PfEMP1 antigen and modelling of PfEMP1 antigen packing on the membrane knobs
}

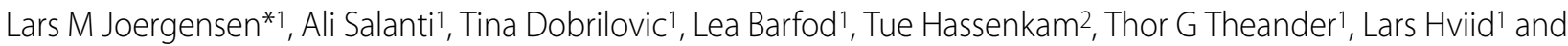
David E Arnot 1,3

\begin{abstract}
Background: Infected humans make protective antibody responses to the PfEMP1 adhesion antigens exported by Plasmodium falciparum parasites to the erythrocyte membrane, but little is known about the kinetics of this antibodyreceptor binding reaction or how the topology of PFEMP1 on the parasitized erythrocyte membrane influences antibody association with, and dissociation from, its antigenic target.

Methods: A Quartz Crystal Microbalance biosensor was used to measure the association and dissociation kinetics of VAR2CSA PfEMP1 binding to human monoclonal antibodies. Immuno-fluorescence microscopy was used to visualize antibody-mediated adhesion between the surfaces of live infected erythrocytes and atomic force microscopy was used to obtain higher resolution images of the membrane knobs on the infected erythrocyte to estimate knob surface areas and model VAR2CSA packing density on the knob.

Results: Kinetic analysis indicates that antibody dissociation from the VAR2CSA PfEMP1 antigen is extremely slow when there is a high avidity interaction. High avidity binding to PfEMP1 antigens on the surface of $P$. falciparuminfected erythrocytes in turn requires bivalent cross-linking of epitopes positioned within the distance that can be bridged by antibody. Calculations of the surface area of the knobs and the possible densities of PfEMP1 packing on the knobs indicate that high-avidity cross-linking antibody reactions are constrained by the architecture of the knobs and the large size of PfEMP1 molecules.

Conclusions: High avidity is required to achieve the strongest binding to VAR2CSA PfEMP1, but the structures that display PfEMP1 also tend to inhibit cross-linking between PfEMP1 antigens, by holding many binding epitopes at distances beyond the 15-18 nm sweep radius of an antibody. The large size of PfEMP1 will also constrain intra-knob cross-linking interactions. This analysis indicates that effective vaccines targeting the parasite's vulnerable adhesion receptors should primarily induce strongly adhering, high avidity antibodies whose association rate constant is less important than their dissociation rate constant.
\end{abstract}

\section{Background}

Antibody responses to parasite-encoded, variable erythrocyte surface antigens (VSA) are a major component in

\footnotetext{
* Correspondence: lars.m.jorgensen@gmail.com

1 Centre for Medical Parasitology, Department of International Health, Immunology \& Microbiology, Faculty of Health Sciences, University of Copenhagen and Department of Infectious Diseases, Copenhagen University Hospital (Rigshospitalet), CSS Øster Farimagsgade 5, Building 22 \& 23, Postbox 2099, 1014 Copenhagen K, Denmark

Full list of author information is available at the end of the article
}

the natural acquisition of immunity to Plasmodium falciparum malaria [1-3]. Biosensors, capable of real-time measurement of the strength of molecular interactions, can be used to measure the kinetics of the antibody binding to the parasite antigen [4] and study the specific mechanisms of how antibodies act against infection [5].

Multi-domain PfEMP1 adhesion receptors are targets for host antibody during malaria infection [6-8]. Both IgG $[6,9]$ and IgM [10] specifically bind purified PfEMP1 anti- 
gens. Non-specific IgG [11] and IgM [12] binding to Plasmodium falciparum-infected erythrocytes (IE) has also been reported, IgM binding being via the $\mathrm{C} \mu 4$ domain [13]. Antibody responses to P. falciparum erythrocyte surface antigens are initiated at a low parasitaemia and class switching from IgM to IgG occurs as the response is boosted by parasite replication [14,15]. Convalescent phase serum antibodies from recovering malaria patients can agglutinate parasites isolated during the previous clinical attack [16]. Cross-reactive antibodies binding malaria parasites from other infections are seen, but broadly reactive sera are rare $[17,18]$.

Electron microscopy (EM) indicates that antibodies bind to the IE surface at the knob protrusions [19-21]. The response is directed against VSAs $[1,22,23]$, but capping of knobs by antibody has not been observed in either EM or fluorescence microscopy (FM) using live IE $[20,24]$. Neither the binding kinetics nor the avidity of these interactions, i.e. the total binding strength of the multiple antibody-antigen interactions, have been measured for this or any other malaria antibody-antigen interaction.

Therefore, a Quartz Crystal Microbalance (QCM) biosensor was used to analyse monoclonal antibody binding to the VAR2CSA PfEMP1 antigen and carry out a kinetic analysis of binding between human anti-PfEMP1 antibodies and recombinant fragments of the VAR2CSA PfEMP1 antigen, under flow conditions. Having immobilized antigen, and antibody in the flow solution, is a more realistic model of the in vivo adhesion reaction than the reciprocal arrangement often used to estimate the 'pure' affinity of antibody-antigen reactions. This configuration also permits estimation of the avidity component [25].

To construct molecular models of the context in which the antibody-PfEMP1 reaction occurs on knob structures, these were first visualized at low resolution, using confocal optical microscopy, then at higher resolution, using atomic force microscopy (AFM) to obtain realistic parameters for structural modeling and consideration of the molecular distances involved in the interaction between epitopes on antigens and paratopes on antibodies.

\section{Methods}

\section{Parasite culture and selections}

Plasmodium falciparum clones 3D7 and FCR3 were cultured in group $\mathrm{O}$ erythrocytes using a modified TragerJensen procedure [20]. Cultures were genotyped using PCR primers targeting MSP2 and GLURP and tested for mycoplasma using the MycoAlert ${ }^{\circ}$ Detection Kit (Lonza). FCR3 cells expressing the var2csa gene and VAR2CSA protein were pre-selected on BeWo cells [26]. 3D7 IE expressing PfEMP1 were selected using streptavidincoated Dynabeads' and biotin-labelled antibodies, to cap- ture parasites reacting with surface-binding antibodies [27].

\section{Antisera and chip-immobilized recombinant antigen}

Rabbit antisera and human monoclonal antibodies targeting the VAR2CSA PfEMP1 protein have been described [28,29]. Affinity-purified rabbit antisera against baculovirus-expressed PfEMP1 VAR4 (from 3D7 ch.4 DBL4, PfD1235w) and VAR5 (from 3D7 ch.11 CIDR, Pf11_0008), each encoded by a different Group A-type var genes [9,30], were used in IFA. Recombinant proteins were purified and characterized as previously described [28-30]. Soluble protein was attached to quartz crystal sensor surfaces as described below.

\section{Confocal microscopy}

A TE 2000-E Nikon Eclipse confocal microscope with $100 \times$ (N.A. 1.4) Apoplan oil immersion lens was used [24]. Images were captured using the EZ-C1 Gold imaging system (version 3.30), saved in IDS test format and processed using Adobe Photoshop software for sharpening edges, contrast and light adjustment. Images show the $5 \mu \mathrm{m}$ size bar calculated by the EZ-C1 software.

\section{Quartz crystal microbalance}

Attana Series 100 biosensors measured molecular interactions in flow, in real time and without labeling. Treated quartz crystal sensor surfaces were positioned in the flow cell with one side of the crystal exposed to continuous flow of protein. As sample reaches the sensor surface, binding of molecules to the crystal surface is detected as a decrease in the resonance frequency of the quartz crystal. The mass bound to the surface was calculated using the Sauerbrey equation [31], with a frequency shift of $1 \mathrm{~Hz}$ corresponding to a bound mass of around $4.4 \mathrm{ng} / \mathrm{cm}^{2}$

\section{Quartz crystal preparation}

Gold plated, $10 \mathrm{MHz}$, AT-cut quartz crystals were purchased from Attana AB (Stockholm). The gold plates were pre-treated either to generate carboxyl groups or with a polystyrene coating. The surface was housed in a cylindrical flow chamber with a volume of $1.25 \mu \mathrm{l}$ (height $50 \mu \mathrm{m}$, diameter $5.64 \mathrm{~mm})$. All buffers and solutions were sterile filtered $(0.2 \mu \mathrm{m})$ before use.

Carboxylated surfaces were used for coupling to amino groups of the protein to be immobilized. The surface was pre-wetted with high quality water $(18.2 \mathrm{M} \Omega \mathrm{cm})$ for $1 \mathrm{~h}$, before insertion into the biosensor housing. The chip surface was allowed to stabilise in a flow of $10 \mathrm{mM}$ HEPES (2- [4-(2-hydroxyethyl) piperazin-1-yl] ethanesulfonic acid) $\mathrm{pH} 7.0$ running buffer. Following stabilisation, the surface was activated by freshly prepared 0.2 M EDC (1ethyl-3-(3-dimethylaminopropyl) carbodiimide), $0.05 \mathrm{M}$ Sulfo-NHS (N-hydroxy-sulfosuccinimide), for 5 minutes. Protein solutions to be immobilized onto the chip surface 
were diluted in $10 \mathrm{mM}$ acetic acid $\mathrm{pH}$ 5.0. Protein was used at concentrations between 5-50 $\mu \mathrm{g} / \mathrm{ml}$, depending on the surface density required, and added by injection into the flow for 5 minutes, after which any remaining active sites were blocked by a $1 \mathrm{M}$ ethanolamine solution $\mathrm{pH} 8.0$ for 5 minutes.

Polystyrene surfaces were used to adsorb proteins. Protein was adsorbed ex situ for three hours at a concentration of $250 \mu \mathrm{g} / \mathrm{ml}$ in a $10 \mathrm{mM}$ acetic acid $50 \mathrm{mM} \mathrm{NaCl}$ solution at $\mathrm{pH}$ 5.0. The kinetic analysis was performed with a running buffer containing $1 \mathrm{~g} / \mathrm{l}$ BSA.

\section{IgG binding and kinetic analysis}

Binding was carried out either at room temperature or $37^{\circ} \mathrm{C}$ (when using the thermo-controlled later version of the Attana 100), using PBS pH 7.4 as the running buffer. After the baseline was stabilised, mock binding runs using running buffer were performed to demonstrate that the stable base line signal was unaffected by the injection process. The buffer baseline signal was subtracted from all measurements. After testing at the chosen concentrations, re-test injections were carried out using the first concentrations tested, to estimate damage to the sensor surface in the course of the experiment. Kinetic data was processed and curves fitted to either a simple 1:1 binding model using software package Scrubber 2 (BioLogic Software Pty Ltd, Campbell, Australia), or a heterogeneity model using ClampXP (Tom Morton and David Myszka, version 3.50). The softwares use the Levenberg-Marquardt method for nonlinear sum of squares error minimization.

\section{Atomic force microscopy}

Magnetically purified $P$. falciparum trophozoite and schizont infected red blood cells were washed and then spread on a glass slide and air dried prior to AFM scanning. The AFM (tapping mode) images of the dried but unfixed IE were recorded in air under ambient conditions with a scan speed of $1 \mathrm{~Hz}$. AFM images were recorded with an Asylum MFP-3D, using a silicon tip (Olympus) with a spring constant of $2 \mathrm{~N} / \mathrm{m}$ and a resonant frequency of $70 \mathrm{~Hz}$.

\section{Results}

Visualizing antibody binding to the erythrocyte surface and the antibody-mediated agglutination reaction

Figure 1 shows the binding phenotypes of fluorescently labeled human IgG antibodies to IE. Figures $1 \mathrm{~A}$ and $1 \mathrm{~B}$ show IE incubated with plasma from the acute phase of a child's malaria attack. Figures $1 C$ and $1 D$ show IE binding plasma antibodies from a sample taken during the convalescence of the child. The 3D7 parasites were pre-selected for binding to anti-PfEMP1 antibodies [32]. Figures 1E and $1 \mathrm{~F}$ show FCR3 parasites stained with an anti-VAR4
PfEMP1 antisera [30]. IE show relatively small amounts of punctate staining with the acute infection serum. Punctate staining with convalescent serum is more intense, indicating maturation of an antibody response targeting concentrations of antigen at particular spots on the IE membrane (compare Figures 1B and 1D).

Figures $1 \mathrm{E}$ and $1 \mathrm{~F}$ show that, using a live staining and purified, specific anti-PfEMP1 antiserum, similar, but more delicately punctate patterns of IE surface staining [20] are obtained compared to crude patient sera. Figures $1 \mathrm{G}$ and $1 \mathrm{H}$ illustrate the capacity [33] of immune serum to mediate agglutination of IE. Antigenic specificity of this adhesion reaction [16] is seen, as those FCR3 parasites expressing particular PfEMP1 antigens [34] which do not bind serum IgG, remain unagglutinated. IE expressing recognized PfEMP1 antigens can thus be agglutinated by cross-linking IgG antibodies. However, the binding strengths of these interactions are not known.

\section{Measuring the strength of binding between anti-PfEMP1 antibodies and a PfEMP1 antigen}

Biosensors can measure anti-PfEMP1 antibody PfEMP1 antigen kinetics and binding strengths and thus give a better understanding of the molecular interactions observed in immunofluorescence. The sensorgrams shown in Figure 2 show the binding of the PAM 4.7 monoclonal antibody [29] to a DBL5 $\varepsilon$ domain fragment of VAR2CSA measured using a QCM biosensor. A 40.1 $\mathrm{kDa}$ recombinant-produced fragment (339a.a. long), containing the DBL5 $\varepsilon$ domain of the VAR2CSA PfEMP1 antigen [35] was bound to either a polystyrene or a carboxyl surface of the quartz crystal. Attachment was detected by a negative resonant frequency shift, which has been converted into more easily analysed positive values in all Figures.

Figure $2 \mathrm{~A}$ shows binding to antigen adsorbed to a polystyrene surface and Figure 2B shows binding to antigen immobilized via a carboxyl group. Resonant frequency changes over time indicate association and dissociation of the antibody to and from its epitope on the VAR2CSA DBL5 $\varepsilon$ antigen. Figure 2 shows that as the concentration of antibody increases, so does the initial rate of binding, essentially a trivial observation, not to be confused with the rate constants $\left(k_{o n}\right.$ and $\left.k_{o f f}\right)$, which are concentrationindependent properties of binding. In Figure 2A, using adsorption to polystyrene as the method of immobilizing antigen, relatively complex biphasic binding kinetics were seen, probably reflecting the situation where some antibody molecules bind two immobilized epitopes, while others only bind one. Thus two of each class of rate constants are given for the reaction. In Figure 2B, with higher concentrations of antigen covalently bound to the surface, simpler kinetics were observed. As in the experiments shown in Figure 2A, the actual reaction is not a 

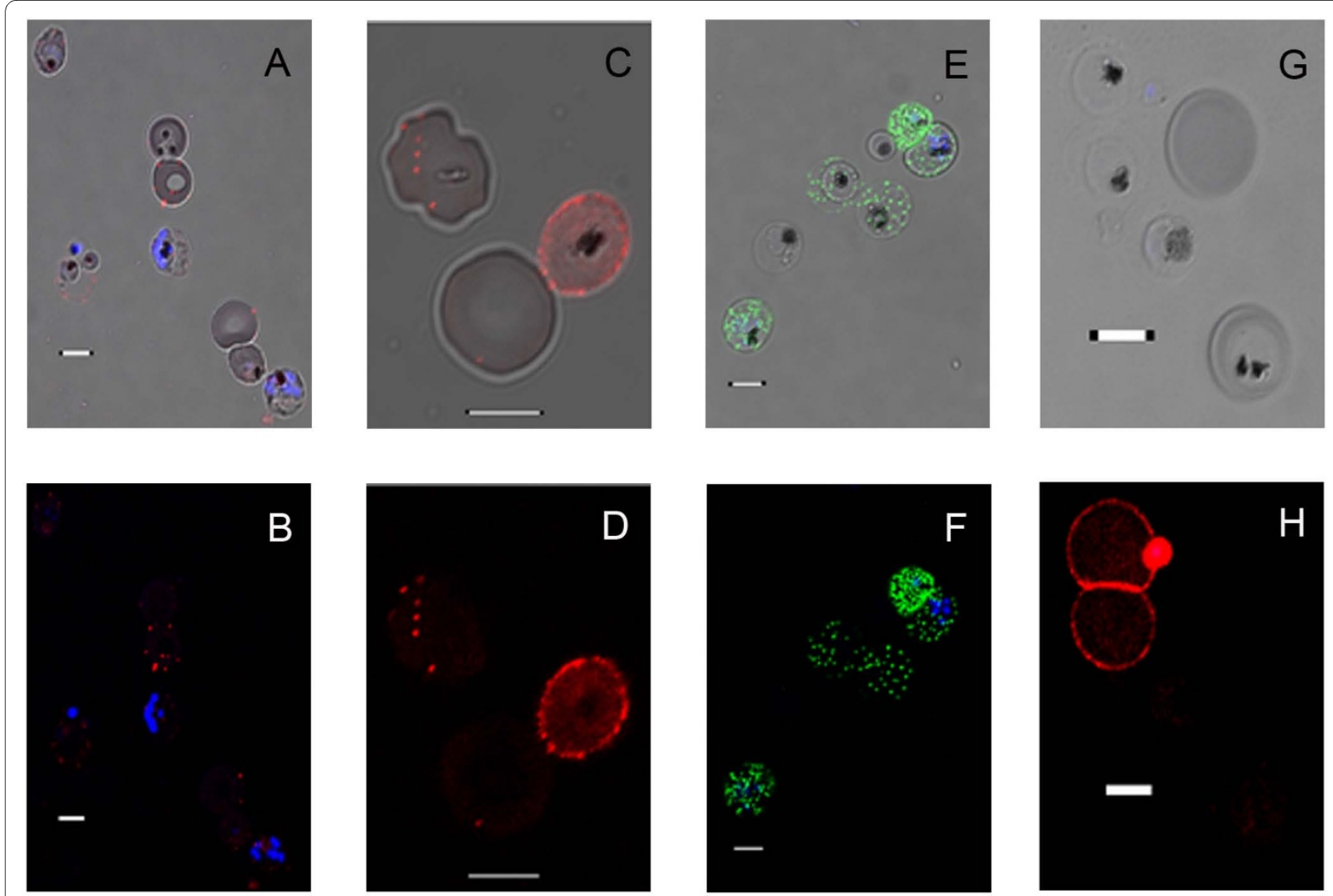

Figure 1 Patient plasma IgG and anti-PfEMP1 IgG binding to IE. IE incubated with goat anti-human IgG conjugated to Alexa"568 (red) or goat anti-rabbit IgG Alexa 488 (green). A. Antibody selected IE (3D7) incubated with 1:50 diluted Tanzanian child's acute-phase malaria serum. The DIC images of IE show DAPI stained parasite nuclei (blue) and spots of membrane-bound lgG (Alexa ${ }^{\circ 568)}$. B. Fluorescence image of Figure 1 A. C. Higher magnification DIC image of live IE (3D7) and uninfected erythrocytes, incubated with 1:100 diluted convalescent plasma from the same child. D

Fluorescence image of Figure 1C. E. DIC images of 3D7, incubated with rabbit antiserum against a recombinant Var4 PfEMP1, detected with goat antirabbit lgG (Alexa"488). F. Fluorescence image of Figure 1E. G. DIC and DAPI (blue) fluorescence image of immune serum-agglutinated and unagglutinated erythrocytes. IE (FCR3) selected by panning on Dynabeads coated with IgG from a pool of semi-immune Tanzanian children's sera (note DAPIstaining merozoite invading the upper IE). H. Agglutination of two IE by serum used in Figures 1C and 1D, detected with goat anti-human IgG Alexa 568 . Two infected and one uninfected erythrocytes are unagglutinated and largely unstained. The invading merozoite is stained by serum IgG. Live trophozoites often do not take up DAPI but such IE can be identified by pigment or serum staining (Figure 1E). Scale bars $5 \mu \mathrm{m}$.

simple 1:1 binding, since there are two Fabs per IgG molecule. However, only the binding of the first paratope gives rise to a frequency shift in this experimental design and although most molecules bind two epitopes, a simple 1:1 binding kinetic equation can adequately describe the observed binding.

Data curves obtained at different antibody concentrations allow more accurate estimation of both the association and dissociation rate constants for PAM 4.7 binding to VAR2CSA DBL5 $\varepsilon$ either adsorbed to a polystyrene surface (Figure $2 \mathrm{~A}$ ) or covalently immobilized on a carboxyl surface (Figure 2B). Mass transport effects were initially estimated, and then minimized, by increasing flow rates. Surface density modulation was also used as a tool to explore avidity effects, as described below. Optimum flow rate was determined in each experiment. The fitting model also takes into account mass transport effects by adding a diffusion step. In Figure 2B, the association/dissociation curve for the binding of PAM 4.7 shows a fairly low binding strength $\left(\mathrm{K}_{\mathrm{D}}=k_{\text {off }} / k_{\text {on }}=1.89 \times 10^{-4} \mathrm{M}^{-1} \mathrm{~s}^{-1} / 6.5\right.$ $\left.\times 10^{3} \mathrm{M}^{-1} \mathrm{~s}^{-1}=2.91 \times 10^{-8} \mathrm{M}\right)$.

Figure 3 shows the binding of a second monoclonal antibody, PAM 3.10 to the DBL5 $\varepsilon$ domain of VAR2CSA. PAM 3.10 has both a higher $k_{\text {on }}$ (Figure 3A: $1.72 \times 10^{5} \mathrm{M}^{-}$ ${ }^{1} \mathrm{~s}^{-1}$, SD $0.028 \times 10^{5} \mathrm{M}^{-1} \mathrm{~s}^{-1}$, Figure 3B: $4.2 \times 10^{6} \mathrm{M}^{-1} \mathrm{~s}^{-1}$, SD $\left.0.05 \times 10^{6} \mathrm{M}^{-1} \mathrm{~s}^{-1}\right)$ and a lower $k_{\text {off }}$ than PAM 4.7. In fact, the PAM $3.10 k_{\text {off }}$ rate is too slow to be measured and there was no visible dissociation. This is a technical limitation of the biosensor as the instrument cannot measure very low dissociation rate constants (below around $10^{-6} \mathrm{~s}^{-}$ 1, Attana AB, pers. comm.). Therefore in this experiment, an exact affinity constant cannot be calculated for the 

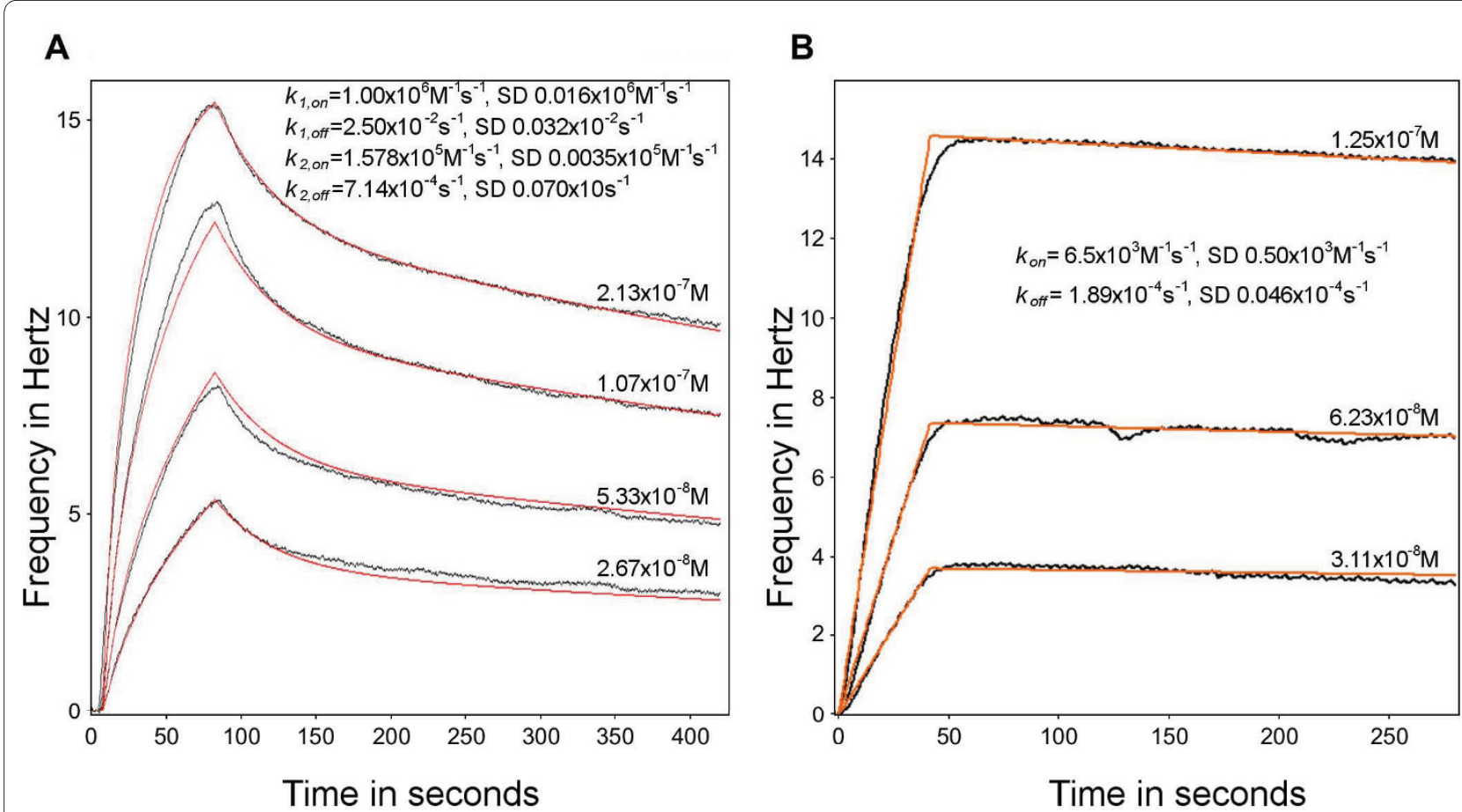

Figure 2 Association and dissociation of a weakly binding antibody to VAR2CSA DBL5 $\boldsymbol{\varepsilon}$. The frequency change ( $\mathrm{Hz}$ ) as a function of time (s), shows both the association and dissociation phase of the PAM 4.7 antibody binding to the DBL $5 \varepsilon$ domain of the VAR2CSA PfEMP1. Black lines indicate data; red lines indicate fitted curves (see Methods) and the calculated rate constants are given on the sensorgrams. A. PAM 4.7, in flow, reacting with VAR2CSA DBL5 $\varepsilon$ immobilized on a polystyrene surface, tested at the four concentrations shown. B. PAM 4.7, in flow, reacting with VAR2CSA DBL5 $\varepsilon$, immobilized on a carboxyl surface and tested at three concentrations with a lower density of surface-immobilized antigen.

PAM 3.10 - antigen interaction. However, assuming $\mathrm{k}_{\text {off }}<$ $10^{-6} \mathrm{~S}^{-1}$ the $\mathrm{K}_{\mathrm{D}}$ would be less than $2.38 \times 10^{-13} \mathrm{M}$. Thus, PAM 3.10 clearly binds more strongly than PAM 4.7 to the same immobilized PfEMP1 antigen fragment. A 10.000 -fold difference in $K_{D}$ based on measurements under avidity conditions would roughly correlate to a 100 -fold difference in $K_{D}$ based on measurements under affinity conditions.

\section{Analysing the avidity of anti-PfEMP1 antibodies by lowering the density of receptors}

To maintain the antibody-in-flow approach while decreasing avidity effects that are apparent in the above experiments, the density of the immobilized PfEMP1 antigen on the chip surface was reduced. Ideally, this would also bring the $k_{\text {off }}$ of strongly binding antibodies into a detectable range. Figure 3 shows the sensorgram results of binding assays of PAM 3.10 reacting with the VAR2CSA DBL5 $\varepsilon$, at different surface densities of immobilized antigen.

In Figure 3B, a low density surface (immobilization frequency shift of $18 \mathrm{~Hz}$ ) was created to carry out a PAM 3.10 binding experiment under conditions less favourable to cross-linking than those used in Figure 3A, which used a high density surface ( $85 \mathrm{~Hz}$ frequency shift). From the immobilization frequency shifts observed and using Equation II (Additional file 1), 20 ng of mass were covalently bound onto the low-density surface chip, from 250 ng injected. During the creation of the higher density surface, $95 \mathrm{ng}$ of protein antigen were covalently bound, from $2500 \mathrm{ng}$ injected into flow (Figure 3A). The absorbed mass can be converted into number of molecules per surface. The low-density surface has $3.0 \times 10^{11}$ molecules and the high-density surface $1.4 \times 10^{12}$ molecules. The estimated distance between bound VAR2CSA DBL $5 \varepsilon$ molecules at low density was $9.8 \mathrm{~nm}$ (Additional file 2). At high density it decreased to $4.5 \mathrm{~nm}$. However, the binding observed in Figure 3 indicates that even after reducing the mass of antigen immobilized on the surface, the $k_{\text {off }}$ remains outside the detectable range. The $k_{\text {on }}$ is increased from the value seen using the high density surface (Figure 3A, $1.72 \times 10^{5} \mathrm{M}^{-1} \mathrm{~s}^{-1}$ ) to $4.2 \times 10^{6} \mathrm{M}^{-1} \mathrm{~s}^{-1}$, i.e. approximately 25 fold. Given that further reductions in immobilized antigen mass leads to problems of markedly decreased sensitivity of specific detection of antibody binding from the flow, the alternative approach of attempting to measure single binding site affinities through the use of Fab fragments was employed. 

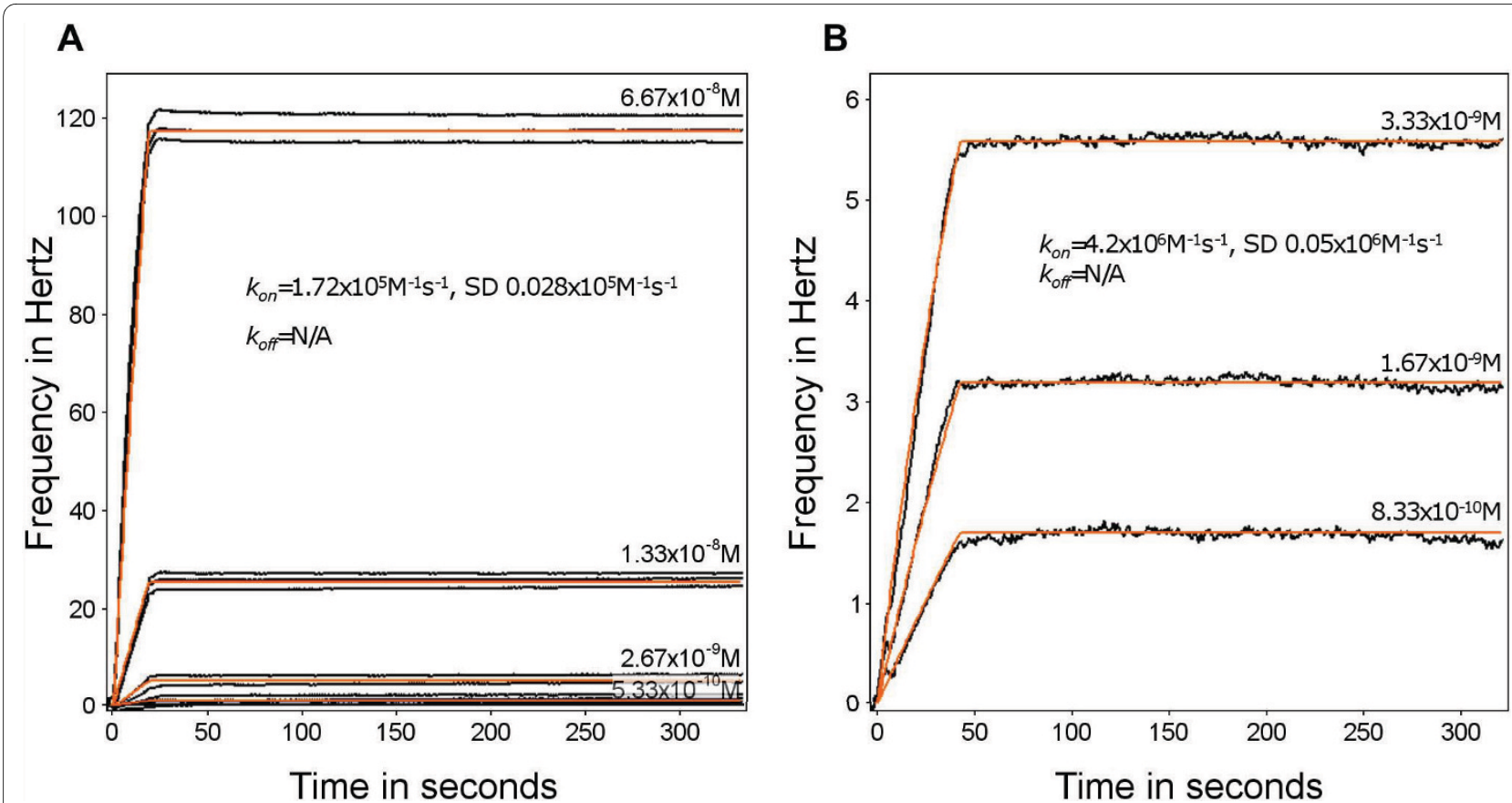

Figure 3 Association and dissociation of a strongly-binding antibody with different surface densities of VAR2CSA DBL5ع. The frequency shift $(\mathrm{Hz})$ is shown as a function of time (s). Black lines represent data from different reactions, with the indicated concentrations of PAM 3.10 binding to VAR2CSA DBL5 $\varepsilon$ immobilized on a carboxyl surface. Red lines indicate the fitted curves, as described in the Methods. The rate constants calculated are given on the sensorgram. A. PAM 3.10, in flow, against a high density surface. B. PAM 3.10, in flow, against a low density surface. See Additional file 1 for surface antigen density calculations.

\section{Measuring the affinity of single antibody binding sites using Fab fragments}

Fab fragments produced by papain cleavage of IgG have a single binding site for antigen [36] and this simplifies analysis and permits direct determination of affinity. The data shown in Figure 4 are from experiments in which Fab fragments of PAM 3.10 were passed in flow over immobilized DBL5e. To increase the strength of the analysis, the curves are fitted only to the dissociation phase, which now occurs, as predicted, in the measurable range with a rate $k_{\text {off }}=4.04 \times 10^{-5} \mathrm{~s}^{-1}$, SD $0.02 \times 10^{-5} \mathrm{~s}^{-1}$.

The $k_{\text {off }}$ value of the Fab fragment describes the off-rate in a single antibody binding-site interaction, i.e. when only one 'arm' of the antibody binds. If an antibody binds without avidity being possible, by chance or due to the distance between epitopes, this would have an off-rate equal to the Fab-fragment off-rate. Avidity being approximately the product of affinities, while whole-antibody off-rates are not exactly Fab fragment off-rates squared, such Fab-derived values give an indication of where the whole-antibody off-rates lie. These quantitative comparisons of anti-PfEMP1 antibody binding strengths are in agreement with qualitative observations that PAM 3.10 is a better IFA staining antibody than PAM 4.7, in that it is useable at lower concentrations to give stronger staining and lower background i.e. a better signal-to-noise ratio.
Modeling PfEMP1 packing onto the knob structures

Both immunofluorescence microscopy and binding kinetic analysis indicate that anti-PfEMP1 antibody binding is influenced by the molecular structures that pack and display these adhesion antigens on the IE surface. To attempt to understand the factors governing the molecular topology and packing of VAR2CSA on knobs, the packing density of the VAR2CSA PfEMP1 on the knob structures was modeled. Since both knobs and PfEMP1 are known to vary considerably in size the available surface area on representative knobs on BeWo-selected IE (FCR3) was measured. This line was used in the antibody assays and is the homologous system for the reagents.

Although knobs were first detected and measured using electron microscopy, in more recent experiments AFM has been used to measure knobs under less denaturing conditions than those used in EM [37-41]. A simple, minimally denaturing AFM mounting methodology was used in these experiments, to scan unfixed IE dried onto microscope cover slips before being glued onto the magnetic AFM holder. Figure 5 shows the knobs on IE (FCR3), as detected using tapping mode AFM in air. The IE shown in Figure 5 were selected for BeWo cell and CSA adhesion and the expression of VAR2CSA antigen, and are recognized by both antibodies used in this study.

Figure $5 \mathrm{~A}$ shows a scan of the early trophozoite surface and Figure $5 \mathrm{~B}$ shows a higher resolution image of two 


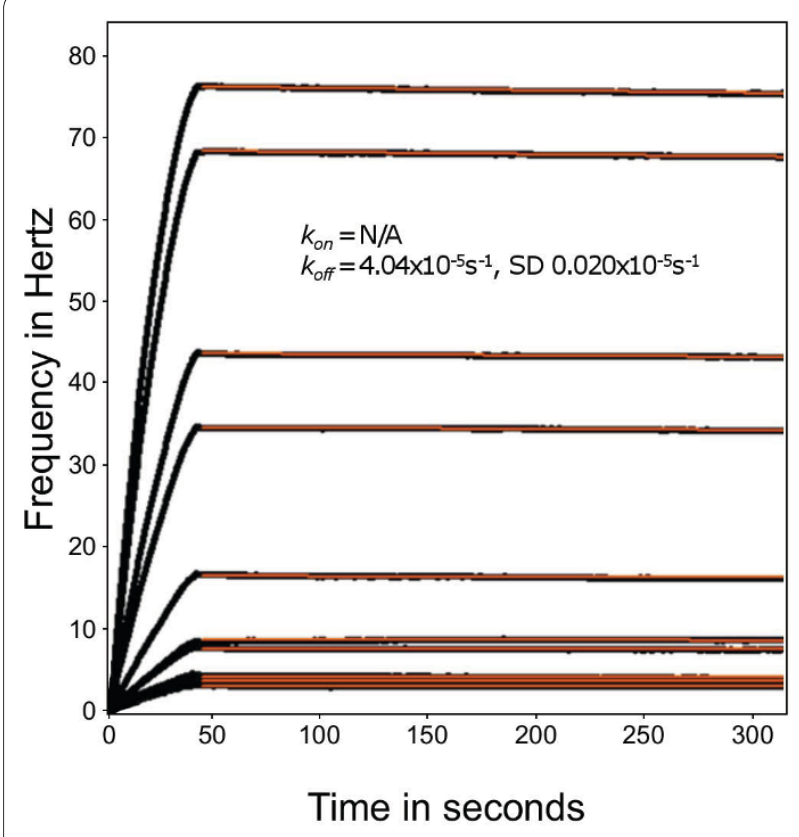

Figure 4 The interaction of monovalent Fab fragment of PAM 3.10 with VAR2CSA DBL5E. Association and dissociation of the Fab fragments of PAM 3.10 to a high density of VAR2CSA DBL5 $\varepsilon$ on the sensor chip surface. The frequency change is shown as a function of time and the black lines show the data from binding experiments with different concentrations of the PAM 3.10 Fab fragment to the surfacebound protein. The red lines show the curve fit for the dissociation phase only. The dissociation rate constant calculated is given on the sensorgram.

knobs, around $250 \mathrm{~nm}$ apart on the membrane. Figures $5 \mathrm{C}$ and 5D show the line of section and contour crosssections respectively. The proximal knob in the IE (FCR3) shown in Figure 5 is $120 \mathrm{~nm}$ in diameter and $24 \mathrm{~nm}$ high and its surface area is around $13,000 \mathrm{~nm}^{2}$ (Additional file 3).

The size and volume of the extracellular domains of VAR2CSA can also be estimated, based on extrapolation from atomic distances derived from recently published crystal structures of the VAR2CSA DBL3x domain $[42,43]$. With the caveat that the packing of the 6 DBL domains is unknown, for the purposes of this exercise in modelling PfEMP1 packing, we assume that VAR2CSA has a globular conformation, rather than a linear 'beadson-a-string' arrangement of domains. The spherical volume of the extracellular $308 \mathrm{kDa}$ of VAR2CSA will be around $840 \mathrm{~nm}^{3}$ (Additional file 4). The diameter of this sphere is $12 \mathrm{~nm}$ and the area on the knob surface covered by a single such VAR2CSA configuration would be around $110 \mathrm{~nm}^{2}$ (Additional file 4). If the knob shown in Figure 5 has a surface area of $13,000 \mathrm{~nm}^{2}$, a maximum of about 110 VAR2CSA molecules could be tightly packed onto this knob, at a density of around 8,000 molecules per $\mu \mathrm{m}^{2}$ (Additional file 4).
It is important to stress that the above measurements and calculations indicate the maximum molecular densities of PfEMP1 proteins with a hypothetical globular conformation. In this study, the knob structures were visualized in AFM to provide molecular measurements in a homologous context and an easily conceptualized model to illustrate the parameters of the problem being analysed. How realistic these assumptions are in estimating PfEMP1 packing on the knobs, and in considering antibody cross-linking and malaria serology, is considered in the Discussion.

\section{Discussion}

Under intense Plasmodium falciparum transmission, immunity to malaria is acquired in childhood. Disease and mortality are concentrated amongst infants and young children, although increased susceptibility to malaria occurs in pregnant women (reviewed in [44]). With successive pregnancies, some immunity to pregnancy-specific malaria is achieved [45]. Immuno-epidemiology $[1,3,46]$ and direct experimentation [47], support a major role for antibody in natural immunity to malaria. Humoral immunity to pregnancy-associated malaria appears to require IgG antibodies against the VAR2CSA antigen, the receptor for chondroitin sulphate $\mathrm{A}$ on the placental syncytiotrophoblast. Our kinetic analysis of antibody binding to VAR2CSA uses monoclonal IgG1 antibodies from EBV-immortalized memory B cells from recently pregnant women living in a malaria endemic area of Africa [29]. The VAR2CSA DBL5 $\varepsilon$ antigen fragment binds to chondroitin sulphate A (CSA) $[35,48,49]$ and both antibodies used in this study react with the surface of CSA-adhering IE in flow cytometry and bind to VAR2CSA DBL5 $\varepsilon$-coated ELISA plates [29].

Measuring association and dissociation of these antibodies to surface-bound VAR2CSA, we have characterized representative low and high avidity antibodies. The high functional affinity of one antibody, PAM 3.10, was indicated by its very low, avidity-dependent, dissociation rate. The binding observed in Figure 3 indicates that even after reducing the mass of antigen on the surface by a factor of around 5, the $k_{\text {off }}$ for PAM 3.10 remained outside the detectable range. This observation is consistent with the Hexagon molecular spacing model calculation of inter-neighbour distances on the sensor surface and the distances measured between IgG1 antibody binding sites. Slow dissociation rates have been reported for other antibodies [25] and have also been proposed to be a manifestation of high avidity, caused by 'rocking' or switching between the two binding sites of a bivalent antibody $[50,51]$.

Reducing the molecular density of antigen on the surface failed to increase the PAM 3.10 antibody dissociation rate to a measurable level. This is probably because cross- 


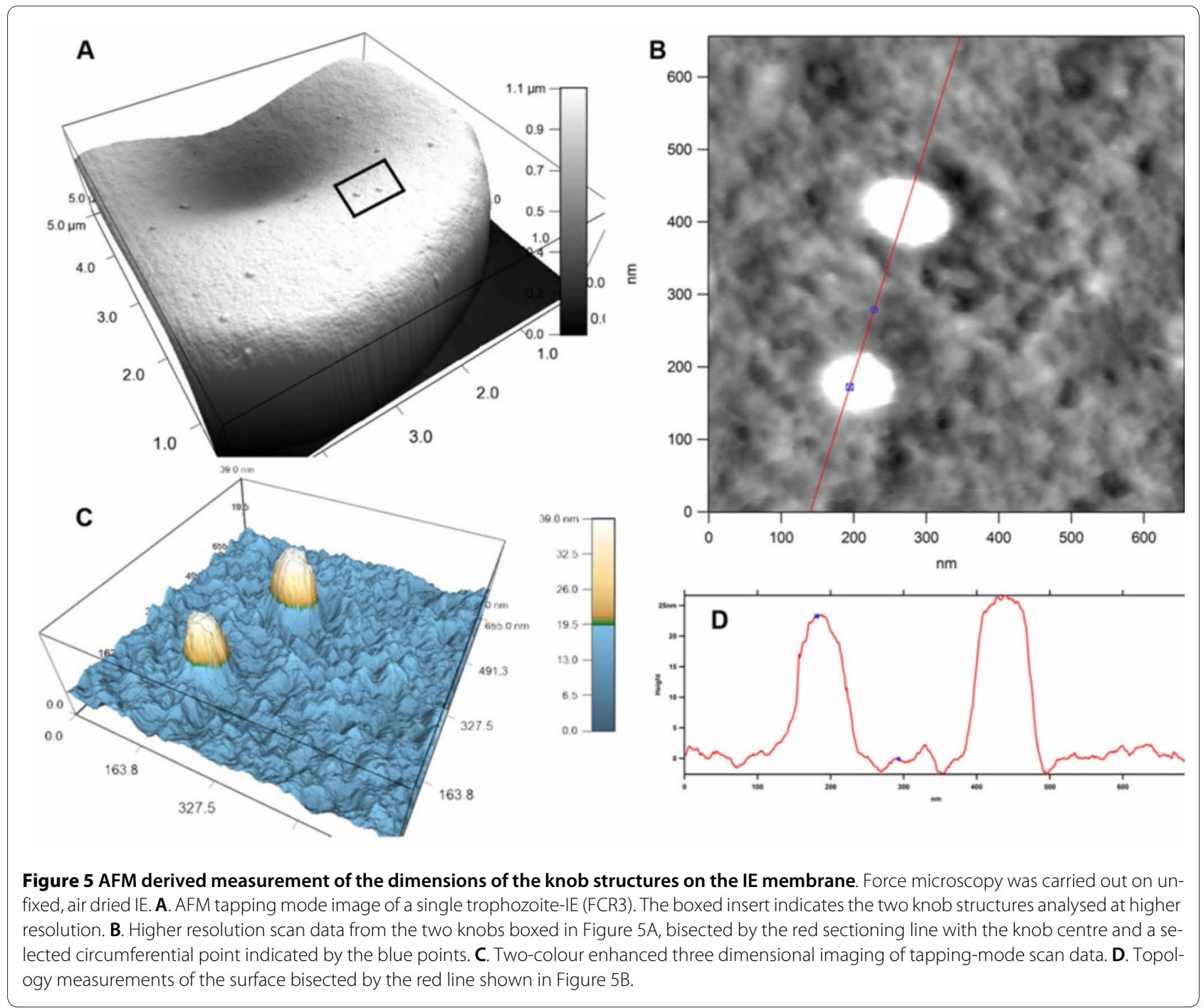

linking interactions between antigens $9.8 \mathrm{~nm}$ apart remains possible for human IgG1 antibodies. Their antigen-to-antigen 'reach' or sweep radius, as measured in co-crystallized antigen-antibody dimers, ranges from 14.2-17-1 nm [52]. However, abolishing bivalent binding by using Fab fragments did lead to a reduction in binding strength. The strength of monovalent binding dropped to a measurable level, comparable, although still greater, than the avidity of a bivalent, but relatively weak-binding antibody, PAM 4.7. This is consistent with the hypothesis that the unmeasurably low dissociation rate constants observed with PAM 3.10 are the result of avidity. Conversely, the lower avidity of PAM 4.7, even where bivalent interaction with the antigen is possible, indicates that its affinity is much lower than the affinity of the PAM 3.10 Fab fragment for the VAR2CSA antigen. This is also seen when comparing the avidity of PAM 4.7 to the affinity of PAM 3.10.
The antibody staining phenotypes of IE seen in Figure 1 confirm that surface reactive IgG binds PfEMP1 in discrete entities dispersed over the erythrocyte surface $[20,21,53]$. Since high avidity binding will play an important role in blocking parasite cytoadhesion and/or precipitating antibody dependent cellular cytotoxicity, it is important to know how easily IgG can cross-link surface PfEMP1. This requires consideration of molecular size, inter-molecular distances and the surface topology of the IE, where the erythrocyte membrane knobs display PfEMP1 [22,54-56]. The PfEMP1 intracellular domain binds knob proteins such as KAHRP and PfEMP3 and link PfEMP1 to the erythrocyte cytoskeleton $[57,58]$ and transmembrane proteins such as Band 3 [59]. Knobs form at actin-spectrin-ankyrin junctions and inter-knob distances are clearly related to the regular inter-junction distances $(100-200 \mathrm{~nm})[60,61]$. This makes antibody crosslinking of PfEMP1 between different knobs on the same erythrocyte by IgG1 (or even IgM) antibodies effectively 
impossible. By virtue of their cytoskeletal anchoring, knobs thus function as avidity reducing structures.

Since avidity strongly influences antibody binding, the question of in vivo access of cross-linking antibody paratopes to surface-exposed PfEMP1 epitopes on the same knob also arises. VAR2CSA is a large molecule with a total mass of $355 \mathrm{kDa}$, of which $308 \mathrm{kDa}$ are in the six surface-exposed DBL domains. The topological parameters influencing intra-knob cross-linking and the establishment of high avidity binding will thus be knob surface area and density, PfEMP1 antigen size and the sweep radius between paratopes. Using EM, knob structures have been estimated to range from 70-150 nm in diameter and between around 10 and $40 \mathrm{~nm}$ in height $[60,62]$. Treating the 'average knob seen in EM' (i.e. in fixed cells prepared for EM, visualized under high vacuum) as sections of a spherical entity with diameter of $100 \mathrm{~nm}$ and height of $15 \mathrm{~nm}$, their surface area can be calculated (Additional file 3) to be $8,600 \mathrm{~nm}^{2}$. For comparison, the surface area of a normal red blood cell is $140 \mu \mathrm{m}^{2}(1.40 \times$ $\left.10^{7} \mathrm{~nm}^{2}\right)$. The AFM-detected knob shown in Figure 5 has a surface area of 13,000 $\mathrm{nm}^{2}$. Assuming a globular structure for VAR2CSA, based on recent crystallographic measurements [43], an estimated maximum of 110 VAR2CSA molecules could be tightly packed onto a knob of the dimensions shown in Figure 5. The Figure $5 \mathrm{knob}$ is a little bigger than the average found in IE (It/A4), but within the range observed in that AFM study [63].

However, a potentially major constraint on PfEMP1 packing density is the fact that knobs remain coated with intra-membranous particles (IMPs) [53,64] composed of host membrane proteins such as Band 3, glycophorin A \& C, Rhesus proteins, CD47, and glucose transporters [65]. Unless the knob IMPs are composed of PfEMP1 without native host protein, which has not been observed, PfEMP1 must share the knob surface with host IMPs, thus further reducing its packing density. The circumferential zone around the knob is visibly depleted of IMPs and could potentially accommodate PfEMP1, in which case around thirty globular VAR2CSA molecules could be packed in a circumferential monolayer around a 120 nm diameter knob. In a rare crystallographic characterization of a membrane protein, a single subunit of rhodopsin (40 kDa) has been shown to occupy a unit volume of $7.5 \mathrm{~nm} \times 4.5 \mathrm{~nm} \times 3.0 \mathrm{~nm}[66,67]$. These tightly packed photoreceptors have an estimated average packing density of 48,300 rhodopsin monomers per $\mu \mathrm{m}^{2}$, compared to our estimated maximum density of 8,000 VAR2CSA molecules per $\mu \mathrm{m}^{2}$.

Given the variability in knob size and the constraints on PfEMP1 packing density, it can be tentatively estimated that VAR2CSA-loaded knobs ranging in diameter between $80-130 \mathrm{~nm}$, will contain around 10-80 of these large antigens. The lower end of these estimates is proba- bly more realistic, particularly if VAR2CSA is more globular than rod-like, as proposed by a recent structural model [68]. The lower end of this estimate is close to a previous estimate of the number of PfEMP1 antigens on a knob, based on immuno-gold labeling of antibodies [53]. The presence of other parasite surface antigens on the knobs will further decrease the potential packing density of PfEMP1.

The density of knobs on the erythrocyte increases as the parasite develops $[41,60]$ although their association with the regularly spaced cytoskeletal junctions determines their final density. Inter-knob distances of less than half the diameter of a knob are not observed $[21,41,53,56,60,64,69]$. Perhaps 1500-2000 knobs appear by the end of intra-erythrocytic development [41], although many fewer are often seen, e.g. in the young trophozoite surface shown in Figure 5. A maximum of 150200,000 closely packed PfEMP1 molecules could thus be displayed on a heavily knobbed cell. Orders of magnitude fewer will be present on sparsely knobbed cells, irrespective of packing.

An established phenomenon in malaria serology, the serum-mediated agglutination of IE, requires cross-linking PfEMP1 molecules on separate erythrocytes [16,18]. Ex-vivo, serum antibodies cross-link IE via parasite VSAs (e.g. Figures $1 \mathrm{G}$ and $1 \mathrm{H}$ ). Broadly agglutinating sera are not observed, indicating the high variability of such antigens. Plasmodium falciparum isolates from pregnant women are also rarely agglutinated by other malaria immune serum [70] and somewhat surprisingly, nor do plasma antibodies from malaria-exposed pregnant women readily agglutinate CSA adhesion-selected parasites [71]. It has been suggested that one reason for this is that high-affinity IgG binding to placental parasites inhibits the binding of potentially agglutinating IgM that is otherwise present in the sample [72]. The finding of very low dissociation rates with these IgG1 antibodies from VAR2CSA supports this hypothesis that IgG1 plays a tight-binding and agglutination-blocking role.

It also seems likely that high avidity antibodies primarily mediate intra- rather than inter-erythrocytic crosslinking. This is supported by the poorly agglutinating nature of the predominantly IgG immune sera isolated from multigravid, malaria-immune women in regions of holoendemic malaria [71]. Somewhat counter-intuitively, it appears that high avidity, strongly binding antibodies are less likely to mediate agglutination than low avidity antibodies, which by being less capable of intra-erythrocytic bivalent binding are more likely to have a paratope available to cross-link other IE.

\section{Conclusion}

In summary, the significance of avid, bivalent binding for high-strength antibody binding to dispersed parasite sur- 
face antigens is shown. Molecular modeling of the PfEMP1-knob-antibody interaction indicates that the large size of PfEMP1 and the architecture of the knobs facilitate cytoadhesion yet may have an inhibitory effect on the avidity of antibody-PfEMP1 binding. Adhesion blocking vaccines should aim to induce strongly adhering, high avidity antibodies that do not dissociate readily from their target antigens. However, the association rate is probably less important in this context.

\section{Additional material}

\section{Additional file 1 Estimating molecular size and surface density. Math-} ematical calculations estimating the size of a molecule based on its molecular mass, and the density of molecules on a surface.

Additional file 2 Topological models and calculations: the hexagon model for molecular distance. Mathematical calculations determining the shortest distance between molecules on a surface assuming a distribution of molecules that maximizes the distances between molecules.

Additional file 3 Topological models and calculations: the area of spherical cross sections and the estimation of knob surface area Mathematical calculations estimating the surface area of a knob assuming the knob is a section of a sphere.

Additional file $4 \mathrm{~A}$ crystallographically aided estimate of the size of a VAR2CSA extracellular monomer. Mathematical calculations estimating the size of VAR2CSA based on knowledge of the size of a single DBL gained from crystallography.

\section{Competing interests}

The authors declare that they have no competing interests.

\section{Authors' contributions}

LMJ and DEA conceived the main hypotheses and experiments, which were largely carried out by LMJ except for the atomic force microscopy experiments carried out by $\mathrm{TH}$ and the confocal microscopy by DB. LMJ performed the kinetic analysis and topological mathematical analyses and calculations. AS, LB, TD, LH and TGT produced antibodies, parasite lines and recombinant antigens and helped analyse the data. DEA and LMJ wrote the manuscript. All authors helped finalise the manuscript. All authors read and approved the final manuscript.

\section{Acknowledgements}

We thank Ms. Dominique Bengtsson for carrying out the confocal microscopy, Mr. Lasse Jensen for advice on mathematical procedures and calculations and Dr. Matt Higgins for crystallographic advice on the VAR2CSA structure and for his comments on a draft of this manuscript.

\section{Author Details}

${ }^{1}$ Centre for Medical Parasitology, Department of International Health, Immunology \& Microbiology, Faculty of Health Sciences, University of Copenhagen and Department of Infectious Diseases, Copenhagen University Hospital (Rigshospitalet), CSS Øster Farimagsgade 5, Building 22 \& 23, Postbox 2099, 1014 Copenhagen K, Denmark, 2Nano-Science Centre, Department of Chemistry, Faculty of Science, University of Copenhagen, Copenhagen K, Denmark and ${ }^{3}$ Institute of Immunology \& Infection Research, School of Biology, University of Edinburgh, West Mains Road, Edinburgh, EH9 3JT, UK

Received: 22 December 2009 Accepted: 19 April 2010 Published: 19 April 2010

\section{References}

1. Bull PC, Lowe BS, Kortok M, Molyneux CS, Newbold Cl, Marsh K: Parasite antigens on the infected red cell are targets for naturally acquired immunity to malaria. Nat Med 1998, 4:358-360.

2. Dodoo D, Staalsoe T, Giha H, Kurtzhals JAL, Akanmori BD, Koram K, Dunyo S, Nkrumah FK, Hviid L, Theander TG: Antibodies to variant antigens on the surfaces of infected erythrocytes are associated with protection from malaria in Ghanaian children. Infect Immun 2001, 69:3713-3718.

3. Giha HA, Staalsoe T, Dodoo D, Roper C, Satti GM, Arnot DE, Hviid L, Theander TG: Antibodies to variable Plasmodium falciparum-infected erythrocyte surface antigens are associated with protection from novel malaria infections. Immunol Lett 2000, 71:117-126.

4. Zhang J, Su XD, O'Shea SJ: Antibody/antigen affinity behavior in liquid environment with electrical impedance analysis of quartz crystal microbalances. Biophys Chem 2002, 99:31-41.

5. Steckbeck JD, Orlov I, Chow A, Grieser H, Miller K, Bruno J, Robinson JE, Montelaro RC, Cole KS: Kinetic rates of antibody binding correlate with neutralization sensitivity of variant simian immunodeficiency virus strains. J Virol 2005, 79:12311-12320.

6. Lusingu JP, Jensen AT, Vestergaard LS, Minja DT, Dalgaard MB, Gesase S, Mmbando BP, Kitua AY, Lemnge MM, Cavanagh D, Hviid L, Theander TG: Levels of plasma immunoglobulin $\mathrm{G}$ with specificity against the cysteine-rich interdomain regions of a semiconserved Plasmodium falciparum erythrocyte membrane protein 1, VAR4, predict protection against malarial anemia and febrile episodes. Infect Immun 2006, 74:2867-2875

7. Mackintosh CL, Christodoulou Z, Mwangi TW, Kortok M, Pinches R, Williams TN, Marsh K, Newbold Cl: Acquisition of naturally occurring antibody responses to recombinant protein domains of Plasmodium falciparum erythrocyte membrane protein 1. Malar J 2008, 7:155.

8. Moll K, Pettersson F, Vogt AM, Jonsson C, Rasti N, Ahuja S, Spångberg M, Mercereau-Puijalon O, Arnot DE, Wahlgren M, Chen Q: Generation of cross-protective antibodies against Plasmodium falciparum sequestration by immunization with an erythrocyte membrane protein 1-Duffy binding-like 1a domain. Infect Immun 2007, 75:211-219.

9. Magistrado $P$, Lusingu J, Vestergaard LS, Lemnge M, Lavstsen T, Turner L, Hviid L, Jensen ATR, Theander TG: Immunoglobulin G antibody reactivity to a Group A Plasmodium falciparum erythrocyte membrane protein 1 and protection from P. falciparum malaria. Infect Immun 2007, 75:2415-2420

10. Semblat JP, Raza A, Kyes SA, Rowe JA: Identification of Plasmodium falciparum var1CSA and var2CSA domains that bind IgM natural antibodies. Mol Biochem Parasitol 2006, 146:192-197.

11. Flick K, Scholander C, Chen Q, Fernandez V, Pouvelle B, Gysin J, Wahlgren M: Role of non-immune lgG bound to PfEMP1 in placental malaria. Science 2001, 293:2098-2100.

12. Creasey A, Staalsoe T, Raza A, Arnot D, Rowe JA: Nonspecific immunoglobulin $\mathrm{m}$ binding and chondroitin sulfate a binding are linked phenotypes of Plasmodium falciparum isolates implicated in malaria during pregnancy. Infect Immun 2003, 71:4767-4771.

13. Ghumra A, Semblat J-P, McIntosh RS, Raza A, Rasmussen IB, Braathen R, Johansen F-E, Sandlie I, Mongini PK, Rowe JA, Pleass RJ: Identification of residues in the $\mathrm{C} \mu 4$ domain of polymeric IgM essential for interaction with Plasmodium falciparum erythrocyte membrane protein (PfEMP1). J Immunol 2008, 181:1988-2000.

14. Krause DR, Gatton ML, Frankland S, Eisen DP, Good MF, Tilley L, Cheng Q: Characterization of the antibody response against Plasmodium falciparum erythrocyte membrane protein 1 in human volunteers. Infect Immun 2007, 75:5967-5973.

15. Kinyanjui SM, Bull P, Newbold Cl, Marsh K: Kinetics of antibody responses to Plasmodium falciparum-infected erythrocyte variant surface antigens. J Infect Dis 2003, 187:667-674.

16. Newbold Cl, Pinches R, Roberts DJ, Marsh K: Plasmodium falciparum: the human agglutinating antibody response to the infected red cell surface is predominantly variant specific. Exp Parasitol 1992, 75:281-292.

17. Bull PC, Lowe BS, Kortok M, Marsh K: Antibody recognition of Plasmodium falciparum erythrocyte surface antigens in Kenya: evidence for rare and prevalent variants. Infect Immun 1999, 67:733-739.

18. Giha HA, Staalsoe T, Dodoo D, Elhassan IM, Roper C, Satti GMH, Arnot DE, Hviid L, Theander TG: Overlapping antigenic repertoires of variant antigens expressed on the surface of erythrocytes infected by Plasmodium falciparum. Parasitology 1999, 119:7-17.

19. Aikawa M, Atkinson CT: Immunoelectron microscopy of parasites. Adv Parasitol 1990, 29:151-214

20. Bengtsson D, Sowa KM, Salanti A, Jensen AT, Joergensen L, Turner L, Theander TG, Arnot DE: A method for visualizing surface-exposed and 
internal PfEMP1 adhesion antigens in Plasmodium falciparum infected erythrocytes. Malar J 2008, 7:101

21. Langreth SG, Reese RT: Antigenicity of the infected-erythrocyte and merozoite surfaces in falciparum malaria. J Exp Med 1979, 150:1241-1254.

22. Baruch DI, Pasloske BL, Singh HB, Bi X, Ma XC, Feldman M, Taraschi TF, Howard RJ: Cloning the P. falciparum gene encoding PfEMP1, a malarial variant antigen and adherence receptor on the surface of parasitized human erythrocytes. Cell 1995, 82:77-87.

23. Biggs B-A, Anders RF, Dillon HE, Davern KM, Martin M, Petersen C, Brown GV: Adherence of infected erythrocytes to venular endothelium selects for antigenic variants of Plasmodium falciparum. J Immunol 1992, 149:2047-2054.

24. Bengtsson DC, Sowa KMP, Arnot DE: Dual fluorescence labeling of surface-exposed and internal proteins in erythrocytes infected with the malaria parasite Plasmodium falciparum. Nature Protocols 2008, 3:1990-1996.

25. Muller KM, Arndt KM, Pluckthun A: Model and simulation of multivalent binding to fixed ligands. Anal Biochem 1998, 261:149-158.

26. Haase RN, Megnekou R, Lundquist M, Ofori MF, Hviid L, Staalsoe T: Plasmodium falciparum parasites expressing pregnancy-specific variant surface antigens adhere strongly to the choriocarcinoma cell line BeWo. Infect Immun 2006, 74:3035-3038.

27. Staalsoe T, Nielsen MA, Vestergaard LS, Jensen ATR, Theander TG, Hviid L: In vitro selection of Plasmodium falciparum 3D7 for expression of variant surface antigens associated with severe malaria in African children. Parasite Immunol 2003, 25:421-427.

28. Barfod L, Nielsen MA, Turner $L$, Dahlbäck M, Jensen ATR, Hviid L, Theander TG, Salanti A: Baculovirus-expressed constructs induce immunoglobulin $G$ that recognizes VAR2CSA on Plasmodium falciparum-infected erythrocytes. Infect Immun 2006, 74:4357-4360.

29. Barfod L, Bernasconi N, Dahlbäck M, Jarrosay D, Andersen PH, Salanti A, Ofori MF, Turner L, Resende M, Nielsen MA, Theander TG, Sallusto F, Lanzavecchia A, Hviid L: Human pregnancy-associated malaria-specific $B$ cells target polymorphic, conformational epitopes in VAR2CSA. Mol Microbiol 2007, 63:335-347.

30. Jensen ATR, Magistrado PA, Sharp S, Joergensen L, Lavstsen T, Chiucchiuini A, Salanti A, Vestergaard LS, Lusingu JP, Hermsen R, Sauerwein R, Christensen J, Nielsen MA, Hviid L, Sutherland C, Staalsoe T, Theander TG: Plasmodium falciparum associated with severe childhood malaria preferentially expresses PfEMP1 encoded by Group A var genes. J Exp Med 2004, 199:1 179-1190.

31. Sauerbrey G: Verwendung von Schwingquarzen zur Wägung dünner Schichten und zur Mikrowägung. Z Phys 1959, 155:206-215.

32. Joergensen $L$, Vestergaard LS, Turner L, Magistrado P, Lusingu JP, Lemnge $M$, Theander TG, Jensen ATR: 3D7-derived Plasmodium falciparum erythrocyte membrane protein 1 is a frequent target of naturally acquired antibodies recognizing protein domains in a particular pattern independent of malaria transmission intensity. J Immunol 2007, 178:428-435.

33. Marsh K, Howard RJ: Antigens induced on erythrocytes by P. falciparum: expression of diverse and conserved determinants. Science 1986, 231:150-153.

34. Wang CW, Magistrado PA, Nielsen MA, Theander TG, Lavstsen T: Preferential transcription of conserved rif genes in two phenotypically distinct Plasmodium falciparum parasite lines. Int J Parasitol 2009, 39:655-664

35. Salanti A, Staalsoe T, Lavstsen T, Jensen ATR, Sowa MPK, Arnot DE, Hviid L, Theander TG: Selective upregulation of a single distinctly structured var gene in CSA-adhering Plasmodium falciparum involved in pregnancyassociated malaria. Mol Microbiol 2003, 49:179-191.

36. Porter RR: The hydrolysis of rabbit y-globulin and antibodies with crystalline papain. Biochem J 1959, 73:119-126.

37. Aikawa M, Kamanura K, Shiraishi S, Matsumoto Y, Arwati H, Torii M, Ito Y, Takeuchi T, Tandler B: Membrane knobs of unfixed Plasmodium falciparum infected erythrocytes: New findings as revealed by atomic force microscopy and surface potential spectroscopy. Exp Parasitol 1996, 84:339-343.

38. Akaki M, Nagayasu E, Nakano Y, Aikawa M: Surface charge of Plasmodium falciparum merozoites as revealed by atomic force microscopy with surface potential spectroscopy. Parasitol Res 2002, 88:16-20.
39. Dvorak JA, Kobayashi S, Abe K, Fujiwara T, Takeuchi T, Nagao E: The application of the atomic force microscope to studies of medically important protozoan parasites. J Electron Microsc (Tokyo) 2000, 49:429-435.

40. Li A, Mansoor AH, Tan KS, Lim CT: Observations on the internal and surface morphology of malaria infected blood cells using optical and atomic force microscopy. J Microbio/ Methods 2006, 66:434-439.

41. Nagao E, Kaneko O, Dvorak JA: Plasmodium falciparum-infected erythrocytes: qualitative and quantitative analyses of parasite-induced knobs by atomic force microscopy. J Struct Biol 2000, 130:34-44.

42. Higgins MK: Overproduction, purification and crystallization of a chondroitin sulfate A-binding DBL domain from a Plasmodium falciparum var2csa-encoded PfEMP1 protein. Acta Crystallogr Sect $F$ Struct Biol Cryst Commun 2008, 64:221-223.

43. Higgins MK: The structure of a chondroitin sulfate-binding domain important in placental malaria. J Bio/ Chem 2008, 283:21842-21846.

44. Hviid $L$ : The immuno-epidemiology of pregnancy-associated malaria: a variant surface antigen-specific perspective. Parasite Immunol 2004 26:477-486.

45. Duffy PE, Fried M: Plasmodium falciparum adhesion in the placenta. Curr Opin Immunol 2003, 6:371-376

46. Hviid L, Staalsoe T: Malaria immunity in infants: a special case of a general phenomenon? Trends Parasitol 2004, 20:66-72.

47. Cohen S, McGregor IA, Carrington S: Gammaglobulin and acquired immunity to human malaria. Nature 1961, 192:733-737.

48. Salanti A, Dahlbäck M, Turner L, Nielsen MA, Barfod L, Magistrado P, Jensen ATR, Lavstsen T, Ofori MF, Marsh K, Hviid L, Theander TG: Evidence for the involvement of VAR2CSA in pregnancy-associated malaria. J Exp Med 2004, 200:1197-1203.

49. Viebig NK, Levin E, Dechavanne S, Rogerson SJ, Gysin J, Smith JD, Scherf A, Gamain B: Disruption of var2csa gene impairs placental malaria associated adhesion phenotype. PLOS ONE 2007, 2:e910.

50. Hudson PJ, Kortt AA: High avidity scFv multimers; diabodies and triabodies. J Immunol Methods 1999, 231:177-189.

51. Muller KM, Arndt KM, Pluckthun A: A dimeric bispecific miniantibody combines two specificities with avidity. FEBS Lett 1998, 432:45-49.

52. Saphire EO, Stanfield RL, Crispin MD, Parren PW, Rudd PM, Dwek RA, Burton DR, Wilson IA: Contrasting IgG structures reveal extreme asymmetry and flexibility. J Mol Biol 2002, 319:9-18.

53. Horrocks P, Pinches RA, Chakravorty SJ, Papakrivos J, Christodoulou Z, Kyes SA, Urban BC, Ferguson DJ, Newbold Cl: PfEMP1 expression is reduced on the surface of knobless Plasmodium falciparum infected erythrocytes. J Cell Sci 2005, 118:2507-2518.

54. Atkinson CT, Aikawa M, Perry G, Fujino T, Bennett V, Davidson EA, Howard RJ: Ultrastructural localization of erythrocyte cytoskeletal and integral membrane proteins in Plasmodium falciparum-infected erythrocytes. Eur J Cell Biol 1988, 45:192-199.

55. Trager W, Rudzinska MA, Bradbury PC: The fine structure of Plasmodium falciparum and its host erythrocytes in natural malarial infections in man. Bull World Health Organ 1966, 35:883-885.

56. Kilejian A, Abati A, Trager W: Plasmodium falciparum and Plasmodium coatneyi: immunogenicity of "knob-like protrusions" on infected erythrocyte membranes. Exp Parasitol 1977, 42:157-164.

57. Oh SS, Voigt S, Fisher D, Yi SJ, LeRoy PJ, Derick LH, Liu S, Chishti AH: Plasmodium falciparum erythrocyte membrane protein 1 is anchored to the actin-spectrin junction and knob-associated histidine-rich protein in the erythrocyte skeleton. Mol Biochem Parasitol 2000, 108:237-247.

58. Waller KL, Nunomura W, Cooke BM, Mohandas N, Coppel RL: Mapping the domains of the cytoadherence ligand Plasmodium falciparum erythrocyte membrane protein 1 (PfEMP1) that bind to the knobassociated histidine-rich protein (KAHRP). Mol Biochem Parasitol 2002, 119:125-129.

59. Magowan C, Nunomura W, Waller KL, Yeung J, Liang J, van Dort H, Low PS, Coppel RL, Mohandas N: Plasmodium falciparum histidine-rich protein 1 associates with the band 3 binding domain of ankyrin in the infected red cell membrane. Biochim Biophys Acta 2000, 1502:461-470.

60. Gruenberg J, Allred DR, Sherman IW: Scanning electron microscopeanalysis of the protrusions (knobs) present on the surface of Plasmodium falciparum-infected erythrocytes. J Cell Biol 1983, 97:795-802. 
61. Aikawa M: Studies on falciparum malaria with atomic-force and surface-potential microscopes. Ann Trop Med Parasitol 1997, 91:689-692.

62. Aikawa M, Udeinya IJ, Rabbege J, Dayan M, Leech JH, Howard RJ, Miller LH: Structural alteration of the membrane of erythrocytes infected with Plasmodium falciparum. J Protozool 1985, 32:424-429.

63. Arie T, Fairhurst RM, Brittain NJ, Wellems TE, Dvorak JA: Hemoglobin C modulates the surface topography of Plasmodium falciparum-infected erythrocytes. J Struct Biol 2005, 150:163-169.

64. Allred DR, Gruenberg JE, Sherman IW: Dynamic rearrangements of erythrocyte membrane internal architecture induced by infection with Plasmodium falciparum. J Cell Sci 1986, 81:1-16.

65. Kodippili GC, Spector J, Sullivan C, Kuypers FA, Labotka R, Gallagher PG, Ritchie K, Low PS: Imaging of the diffusion of single band 3 molecules on normal and mutant erythrocytes. Blood 2009, 113:6237-6245.

66. Mustafi D, Palczewski K: Topology of class A G protein-coupled receptors: insights gained from crystal structures of rhodopsins, adrenergic and adenosine receptors. Mol Pharmacol 2009, 75:1-12.

67. Palczewski K, Kumasaka T, Hori T, Behnke CA, Motoshima H, Fox BA, Le TI, Teller DC, Okada T, Stenkamp RE, Yamamoto M, Miyano M: Crystal structure of rhodopsin: A G protein-coupled receptor. Science 2000 289:739-745.

68. Andersen P, Nielsen MA, Resende M, Rask TS, Dahlbäck M, Theander T, Lund O, Salanti A: Structural insights into epitopes in the pregnancyassociated malaria protein VAR2CSA. PLoS Pathog 2008, 4:e42.

69. Rug M, Prescott SW, Fernandez KM, Cooke BM, Cowman AF: The role of KAHRP domains in knob formation and cytoadherence of $P$. falciparum-infected human erythrocytes. Blood 2006, 108:370-378.

70. Beeson JG, Brown GV, Molyneux ME, Mhango C, Dzinjalamala F, Rogerson SJ: Plasmodium falciparum isolates from infected pregnant women and children are associated with distinct adhesive and antigenic properties. J Infect Dis 1999, 180:464-472.

71. Ricke CH, Staalsoe T, Koram K, Akanmori BD, Riley EM, Theander TG, Hviid $L$ : Plasma antibodies from malaria-exposed pregnant women recognize variant surface antigens on Plasmodium falciparum-infected erythrocytes in a parity-dependent manner and block parasite adhesion to chondroitin sulphate A. J Immuno/ 2000, 165:3309-3316.

72. Elliott SR, Brennan AK, Beeson JG, Tadesse E, Molyneux ME, Brown GV, Rogerson SJ: Placental malaria induces variant-specific antibodies of the cytophilic subtypes immunoglobulin G1 (IgG1) and IgG3 that correlate with adhesion inhibitory activity. Infect Immun 2005, 73:5903-5907.

doi: 10.1186/1475-2875-9-100

Cite this article as: Joergensen et al., The kinetics of antibody binding to Plasmodium falciparum VAR2CSA PFEMP1 antigen and modelling of PfEMP1 antigen packing on the membrane knobs Malaria Journal 2010, 9:100

Submit your next manuscript to BioMed Central and take full advantage of:

- Convenient online submission

- Thorough peer review

- No space constraints or color figure charges

- Immediate publication on acceptance

- Inclusion in PubMed, CAS, Scopus and Google Scholar

- Research which is freely available for redistribution

Submit your manuscript at www.biomedcentral.com/submit
C Biomed Central 